\title{
Correspondence
}

\section{Horner's syndrome due to epidural analgesia}

To the Editor:

Horner's syndrome is an unusual ${ }^{1}$ but recognized complication of epidural anesthesia. ${ }^{2,3}$ We report a case of Horner's syndrome occuring during post operative epidural analgesia in a non-pregnant woman.

A 21 -yr-old, $80 \mathrm{~kg}$, ASAII, woman with Crohn's disease had an elective ileocaecal resection. A 20-guage epidural catheter was placed at the $T_{6.7}$ level and $3 \mathrm{ml}$ bupivacaine $0.5 \%$ with epinephrine were administered. General anaesthesia was induced with sufentanil and propofol, and was maintained with $\mathrm{N}_{2} \mathrm{O} / \mathrm{O}_{2}$ and and isoflurane. Another $2 \mathrm{ml}$ bupivacaine $0.5 \%$ with epinephrine and $2 \mathrm{mg}$ preservative-free morphine were given during surgery. On arrival in the PACU, $3 \mathrm{ml}$ lidocaine $1.5 \%$ $\mu \mathrm{g} \cdot \mathrm{ml}^{-1}$ fentanyl solution was started at a rate of $8 \mathrm{ml} \cdot \mathrm{hr}^{-1}$.

Twenty hours after the infusion was started, she complained of "heaviness of the right eye lid and swelling of the right eye". Examination revealed right ptosis, miosis and conjuctival injection. ${ }^{4}$ A diagnosis of right Horner's syndrome was made. The sensory block was $T_{4-10}$. Bupivacaine was stopped and replaced by hydromorphone $\left(0.05 \mathrm{mg} \cdot \mathrm{ml}^{-1}\right)$ at $3 \mathrm{ml} \cdot \mathrm{hr}^{-1}$. Horner's syndrome resolved in $30 \mathrm{~min}$. One hour and $45 \mathrm{~min}$ later, she complained of pain at rest. Bupivacaine/fentanyl was re-introduced at $8 \mathrm{ml} \cdot \mathrm{hr}^{-1}$. Hydromorphone was stopped $45 \mathrm{~min}$ later and the right side ptosis and miosis reappeared. Examination revealed no sensory block. The bupivacaine/fentanyl infusion was again discontinued and the Horner's syndrome resolved in two hours. Satisfactory analgesia was achieved with IV-PCA using morphine, and NSAID $p o / p r$.

Kathy Fan MD, Ian Morris MD FRCPC, Gordon Launcelott MD FRCPC

Halifax, Nova Scotia

\section{REFERENCES}

1 Moban J, Potter JM. Pupillary constriction and ptosis following caudal epidural analgesia. Anaesthesia 1975; 30: 769-73.

2 Skaredoff MN, Datta S. Horner's syndrome during epidural anaesthesia for elective Caesarean section.

Can Anesth Soc J 1981; 28: 82-5.

3 Clayton KC. The incidence of Horner's syndrome dur- ing lumbar extradural for elective Caesarean section and provision of analgesia labour. Anaesthesia 1983; 38: 583-5.

4 Schachner SM, Reymolds $A C$. Horner syndrome during lumbar epidural analgesia for obstetrics. Obstet Gynecol 1982; 59: S31-2.

\section{Epidural analgesia for labour}

To the Editor:

In the Abstract for the article "Epidural analgesia for labour and delivery: informed consent issues", the authors stated that "the level of satisfaction with the consent process was 8.1/10". In the article, the authors reported that patients with side effects and patients without side effects had satisfaction levels of $3.1 / 10$ and $7.1 / 10$, respectively. We failed to see how combining the two groups would produce a higher level of satisfaction than the individual groups. Was one of the numbers misprinted?

\section{B.Y. Ong MD FRCPC}

R. Segstro MD FRCPC

D. Paetkau MD FRCPC

Winnipeg, Manitoba

\section{REFERENCE}

1 Pattee $C$, Ballantyne $M$, Milne $B$. Epidural analgesia for labour and delivery: informed consent issues. Can J Anaesth 1997; 44: 918-23.

\section{REPLY:}

You questioned the differences in means that relate to the patients' level of satisfaction with the consent process upon receiving the epidural. You noted that the mean level of overall satisfaction with the consent process, as stated in the abstract, was 8.1 which was calculated from question \#57. You asked bow this mean of 8.1 could be true if the mean level of satisfaction of the side effect and no side effect groups are 3.1 and 7.1 respectively.

This occurs because the data used to calculate the two group means, when we compared the side effect group and the no side effect group, came from a DIFFERENT question in the survey, \#35, that asked the patient how satisfied they were with the information they received (ie. 
the consent process) with regard to the SIDE EFFECTS OF THE LOCAL. As means of different measures, there is no relationship between them.

For the latter question, the entive sample mean was 6.8 and the standard deviation was 4.18 with an $n=60$. The side-effect group of $n=18$ had a mean of $3.1 \pm 4.14$. The no side-effect group of $n=48$ had a mean of $7.1 \pm$ 4.16.

I hope this gives a clearer picture of the results. In retrospect, we recognize that we should have reiterated and fully explained the overall mean level of satisfaction of 8.1 in the results section as this truly was the crucial result of the study.

Margaret Ballantyne

Brian Milne MD MSC FRCPC

Carol Pattee MD FRCPC

Kingston, Ontario

\section{Tuoby needles and CSE}

To the Editor:

All $8.9 \mathrm{~cm}$ ( 3.5 inches) Tuohy needles are not equal in length. Combined spinal-epidural anaesthesia is now part of our everyday practice. Cerebrospinal fluid (CSF) is usually easily obtained, provided a special $11.90 \mathrm{~cm}$ (4 11/16 inches, Becton-Dickenson, Franklin Lakes, NJ, USA) spinal needle is inserted through the $8.9 \mathrm{~cm}$ Tuohy needle. We recently encountered a situation forcing us to replace our usual epidural tray (Baxter, Deerfield, IL, USA) with material manufactured by Preferred Medical Products (Thorold, Ontario, Canada). We then experienced difficulties obtaining free flow of CSF with this new material. Although the length of the shaft of the needles is the same for both

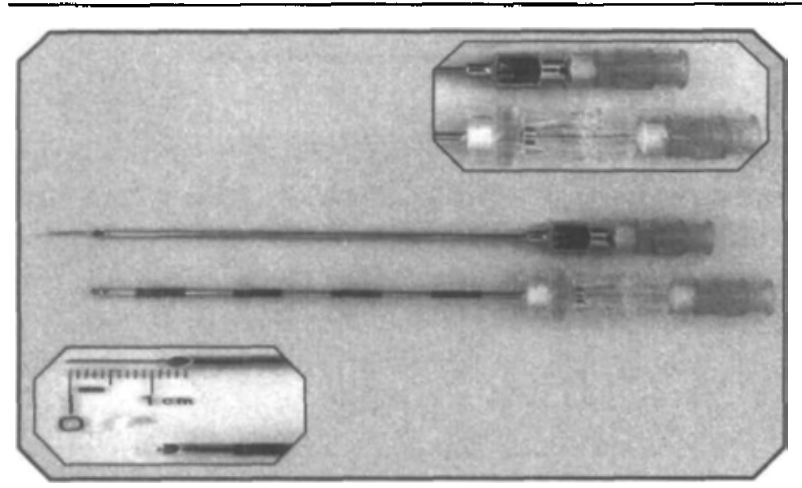

FIGURE: Top - Baxter Tuohy needle; bortom - PMP necdle. A Becton-Dickenson $11.90 \mathrm{~cm}$ Whitacre $\# 27$ needle is inserted in both. manufacturers, the length of the hub is longer in the second needle, providing only one $\mathrm{mm}$ protrusion of the spinal needle at the end of the Tuohy needle, while with the first epidural kit, needle protrusion is approximately $1.2 \mathrm{~cm}$ (Figure). The problem disappeared when the first epidural kit became available again.

\section{Michel Girard MD MHPE FRCPC \\ Pierre Drolet MD FRCPC \\ Montréal, Québec}

\section{Fibreoptic cart for intubation and teaching}

To the Editor:

The efficiency of fibreoptic intubation and teaching depend heavily on all necessary equipment and intubation aids being immediately available. ${ }^{1}$ For this reason we have compiled a special fibreoptic intubation cart to make sure all needed equipment is readily at hand (Figure).

The fibreoptic intubation cart can also be used for the training and teaching of all staff and trainees in fibreoptic intubation techniques. Use of the cart for both routine clinical practice and for teaching offers obvious economic advantages. Especially the videorecorder enables us to use this cart for instruction purposes. All airway management equipment used in our hospital is available on the cart and is listed in the Table.

The cart is used for both predicted and unexpected difficult intubations. The cart has a fixed location in the operating theatre complex, where it is returned after use. The fibreoptic bronchoscope is cleaned and desinfected after use during which time we have a second bronchoscope available

Chris Mallios MD

Marcel de Quelerij MD

Patricia Gerritsen $M D$

Georgio Medici MD

Frans V. Poorten MD

Erasmus University Rotterdam-Dijkzigt

Rotterdam, the Netherlands

\section{REFERENCES}

1 Benumof JL. Airway Management Principles and Practice. Mosby Year Book, 1996: 289, Fig 16-4.

2 Mallios C. A modification of the Laerdal anaesthesia mask for nasotracheal intubation with the fibreoptic laryngoscope. Anaesthesia 1980; 35: 599-600. 